\title{
Research on the Integration of BIM Technology in Prefabricated Buildings
}

\author{
Yuge Wang, Yueming Wang \\ School of Civil Engineering and Architecture, Southwest University of Science and Technology, Mianyang, China \\ Email:2311695090@qq.com
}

How to cite this paper: Wang, Y.G. and Wang, Y.M. (2021) Research on the Integration of BIM Technology in Prefabricated Buildings. World Journal of Engineering and Technology, 9, 579-588.

https://doi.org/10.4236/wjet.2021.93040

Received: July 13, 2021

Accepted: August 3, 2021

Published: August 6, 2021

Copyright (อ 2021 by author(s) and Scientific Research Publishing Inc. This work is licensed under the Creative Commons Attribution International License (CC BY 4.0).

http://creativecommons.org/licenses/by/4.0/ (c) (i) Open Access

\begin{abstract}
Today we are in a technologically explosive information society. The crossborder integration of manufacturing and construction is prefabricated buildings. The cross-border integration of construction and IT is BIM technology, and the emergence of BIM technology provides new ideas for prefabricated building, and the integration of prefabricated building and BIM technology realizes the construction industrialization. This paper studies the application of BIM technology in prefabricated buildings, including the design phase, construction and assembly phase, operation and maintenance phase, and application analysis of related software, so as to improve the high efficiency, high quality and high precision development of prefabricated projects, and promote domestic green environmental protection. The development of the construction industry provides reference value for the application of BIM technology in prefabricated buildings.
\end{abstract}

\section{Keywords}

Prefabricated Building, BIM Technology, Design, Construction, Operation and Maintenance

\section{Introduction}

In recent years, China's construction industry has developed rapidly and made outstanding contributions to China's economic development. The burden of high input, low output, serious environmental pollution, high energy consumption and high emissions brought by traditional building technology has made prefabricated buildings a hot spot at home and abroad, and prefabricated buildings have high construction efficiency, energy saving and environmental protection, save manpower, low resource consumption and other advantages [1]. In 2016, the country took prefabricated buildings as a key development object to promote the 
transformation and upgrading of industrial structure. In 2017, the Ministry of Housing and Urban-Rural Development clearly proposed that prefabricated buildings should account for more than $15 \%$ of new buildings in the country by 2020 , including $20 \%$ in key areas, and more than $50 \%$ by 2025 . Under the current social background, the development of prefabricated buildings is of urgency. It has received widespread attention from the society and has gradually become the future development trend of the construction industry.

In particular, in early January 2020, in order to cope with the shortage of beds caused by the outbreak of the epidemic, Wuhan City completed the construction of "Huoshen Mountain" and "Thunder Mountain" hospitals in just 15 days. In early March, Seoul University Hospital of South Korea ordered two "Vulcan Mountain" hospitals from China's Broad Group, and the installation is expected to be completed within 2 days. On March 2, the Ministry of Human Resources and Social Security, the State Administration of Market Supervision and the National Bureau of Statistics jointly announced 16 new occupations to the public, including prefabricated construction workers. The epidemic has promoted the development of prefabricated buildings. It is precisely because of the integration of BIM technology and prefabricated buildings that the hospital construction task with a lot of equipment, high exhaust requirements, and intricate pipelines can be completed in just a few days. In the field of modern construction, it is the integration of BIM technology that provides new ideas for prefabrication, further promoting the application of prefabricated buildings in the modern construction industry, which is conducive to the overall improvement of building quality, and thus promotes the development of the construction industry.

Wang Ailing [2] used entropy weight method and grey clustering method to evaluate the BIM application ability of prefabricated buildings. Xu Liqiang [3] discussed the application advantages and methods of BIM technology in assembly building safety management. Xu Pengfei [4] studied the application of BIM in the whole construction process of prefabricated buildings. With the help of Revit software, he built a model to monitor and track the whole construction process in real time. Gao Peng [5] designed prefabricated concrete frame structure of single building based on PKPK-BIM system, and gave tree solutions to key problems of collision. Fan Hua [6] be simulated through BIM related software technology, and an information platform could be established before construction to determine the design scheme. Li Yaping [7] discussed the methods and means to realize the in-depth design of prefabricated buildings based on BIM technology, and proposed the application problems of BIM in prefabricated buildings at present. Wang Shuqiang [8] proposed that prefabricated building projects can adopt EPC management mode to realize the information integration of each project stage on the basis of BIM technology. Literature research mainly focus on BIM one specific application problems in prefabricated buildings, for prefabricated buildings full life cycle each stage and the analysis of the 
software application is less, based on this, this paper mainly study BIM in assemble prefabricated construction design stage, construction stage, operational phase and the analysis of the related software applications.

\section{Overview of Prefabricated Buildings}

The concept of prefabricated building has been mentioned as early as the 1920s, mainly originated from the construction industrialization in Germany and other developed European countries. Prefabricated building is the production and processing of a large number of on-site operations in the prefabricated components factory, and the installation is completed in the construction site. [9] Prefabricated buildings have the advantages of low-carbon economy, green environmental protection, energy-saving, high-efficiency, and high-quality. It is the general trend and can achieve the three goals of controllable quality, controllable cost, and controllable progress in the project development process [10]. Compared with traditional building construction, it has the following advantages:

One is the transformation of the working space, which has realized the transformation from "field" to "factory", avoiding the large amount of waste residue and residual waste generated by on-site pouring, and the production operation is not restricted by external environmental factors, such as weather conditions, humidity, and temperature, Temperature difference, etc. can be controlled in the factory.

Second, in the aspect of green energy-saving, production in the factory to minimum the influence of the outside world, such as noise, dust, air, urban landscape, etc., at the same time prefabricated building's new fabricated and sustainable technologies, adopt new materials with high quality production and assembly building components, conform to the requirements of the national housing industrialization and the energy conservation and emissions reduction, is beneficial to energy conservation and environmental protection. Therefore, prefabricated building is the inevitable trend to promote the development of green building.

Third, in terms of construction precision and construction quality, it has changed from engineering construction to engineering manufacturing, and from extensive management to refined, standardized, and process-oriented management in management methods. The components produced in factories usually reach higher quality standards than those produced on the construction site.

Fourth, in terms of operating conditions and construction efficiency, the technically difficult and dangerous processes can be replaced by the mechanical arm, The construction speed is fast and manpower is saved, the corresponding site construction safety risk is greatly reduced, and the factory component construction and site installation and commissioning can be synchronized.

The prefabricated building has become the backbone of the construction industry in China, and the hidden safety problems of many traditional cast-in-place buildings have been greatly improved. 


\section{BIM Technology Overview}

\subsection{BIM Technology Theory}

In building construction, manual drawing was at the beginning, and CAD technology also subverted the traditional drawing method, which made the drawing more convenient, and then completed the construction drawing work with tight schedule and high complexity. The concept of BIM was born in the 1970s. When BIM technology appeared, prefabricated buildings were relatively mature. BIM (Building Information Modeling) is a data tool applied to engineering design, construction and management. Through the integration of the Building data and Information model, it is shared and transmitted in the whole life cycle process of project planning, operation and maintenance. It enables engineering and technical personnel to correctly understand and efficiently respond to various construction information, and provides a foundation for all construction subjects including planning, design, construction, supervision and operation units to work together. It plays an important role in improving production efficiency, saving costs and shortening construction period [11].

Unlike CAD, BIM is not the building information is stored in the drawings, but the information stored in a visual model, all kinds of graphics and project reports can be real-time dynamically generated from the model file, any aspect of changes in the model can be updated in real time, ensure the consistency of the data and the latest.

\subsection{Introduction of BIM Common Software}

At present, The commonly used BIM software in the construction industry includes modeling software Revit/Bentley/Archicad, structural analysis software Etabs/Syaad, electromechanical analysis software Trane Trace, visualization software 3DS Max/Lumion, sustainability analysis software IES, and in-depth design software Tekla Structures, model collision software Navisworks, powerful Project management software Microsoft Project, as well as PKPM-BIM collaborative design system platform, the functions of each software are different, and the coordination of each software is beneficial to the best effect [12]. The specific differences are shown in Table 1 below.

\section{Application of BIM in Prefabricated Buildings}

The traditional construction mode of prefabricated buildings, in the three stages of design, construction, and management, is usually considered to be separated and the design is unreasonable. The final problem can only be found in the installation process, causing changes and waste. In recent years, when the country strongly advocates prefabricated buildings, BIM intrusion is a kind of innovation in the production mode of prefabricated buildings. The core of prefabricated buildings is "integration", and BIM technology is an effective means of "integration", which connects the whole process of design, production, construction, decoration and management, and serves the whole life cycle of prefabricated 
Table 1. Introduction of BIM commonly used software.

\begin{tabular}{|c|c|}
\hline software & function \\
\hline $\begin{array}{l}\text { Revit } \\
\text { Modeling, collision checking, } \\
\text { and compatibility with other } \\
\text { software }\end{array}$ & $\begin{array}{l}\text { Conduct modeling, model analysis and conflict inspection for } \\
\text { architecture, structure, electromechanical and other majors; } \\
\text { Compatible with other software links, data sharing and parametric } \\
\text { design, to modify a certain problem can be automatically updated } \\
\text { and modified for other software. }\end{array}$ \\
\hline $\begin{array}{l}\text { PKPM-BIM } \\
\text { collaborative design system }\end{array}$ & $\begin{array}{l}\text { Compilated in accordance with Chinese standards and design codes, } \\
\text { PKPM-BIM can realize functions such as model building, component } \\
\text { splitting, collision inspection and construction simulation, realize } \\
\text { full-professional collaborative design including building, structure } \\
\text { and equipment electromechanical, and seamlessly connect with } \\
\text { existing structural software. }\end{array}$ \\
\hline $\begin{array}{l}\text { 3DS Max/Lumion } \\
\text { Visual rendering software }\end{array}$ & $\begin{array}{l}\text { 3DS Max: powerful animation production capabilities, stackable } \\
\text { modeling steps, used in architectural design, three-dimensional } \\
\text { animation and engineering visualization. } \\
\text { Lumion: Simple and fast rendering software for architecture, } \\
\text { planning and design, rendering video images with high definition } \\
\text { effects through virtual scenes. }\end{array}$ \\
\hline $\begin{array}{l}\text { Navisworks } \\
\text { Collision check and progress } \\
\text { simulation }\end{array}$ & $\begin{array}{l}\text { Clash Detective: Collision check to reduce human error in design. } \\
\text { Timeliner: Using animated images to display the simulation } \\
\text { structure, and has the function of automatic update. }\end{array}$ \\
\hline $\begin{array}{l}\text { Tekla Structures } \\
\text { Deeper Design Software }\end{array}$ & $\begin{array}{l}\text { Fully integrated 3D solid structure model and structural analysis, 3D } \\
\text { steel structure detail design, 3D reinforced concrete design, automati } \\
\text { Shop Drawing, BOM table automatic generation system. }\end{array}$ \\
\hline $\begin{array}{l}\text { Microsoft Project } \\
\text { Project management } \\
\text { application software }\end{array}$ & $\begin{array}{l}\text { Develop plans quickly and accurately, and effectively control analysis } \\
\text { progress and costs. }\end{array}$ \\
\hline
\end{tabular}

buildings. The integrated application of BIM technology in prefabricated buildings can effectively improve the efficiency of architectural design, help the continuous optimization of architectural design plans, and further promote the development of the construction industry. In the actual application process, BIM is used in the design stage, production and transportation of prefabricated buildings. The stage as well as the construction and assembly stage play a vital role.

\subsection{Application of BIM Technology in the Prefabricated Building Design Stage}

\subsubsection{Fine and Parametric Modeling}

In building construction, manual drawing is the first step. The emergence of CAD technology subverts the traditional way of drawing, and then the drawing work with a tight schedule and a high degree of complexity can be completed. The integration of BIM further promotes the development of the construction industry. The commonly used modeling software in BIM is Revit, which can be compatible and linked with other software to share data resources. Through the application of BIM technology, pipes and lines can be accurately reserved, even small screw holes, and the names and quantities of various components can be 
shown through the detailed list. It also can realize parametric design, mass and rapid adjustment of component size, reinforcement layout and hole position, and even can be generated with one key, which can meet the visual collaborative design of various professions and participants, and achieve information and fine modeling [13].

\subsubsection{D Visual Collaborative Design}

At present, the completion of most construction projects requires multi-disciplinary collaboration of design units. The traditional method requires each professional designer to independently complete the construction drawing design, and repeated consultation, modification, optimization, and verification are required to minimize the details of the problem [14]. Visual collaborative design based on BIM technology can realize the collaborative design of various professions and all participants. Each profession is responsible for the module editing of the profession, and multiple professions edit and modify the same 3D model, which can not only connect the design, production, construction, and decoration of prefabricated buildings in series. The whole process of management and management makes the design process run smoothly, and can also reduce the amount of drawings, effectively solve the collision problems that may occur between professionals and prefabricated components, and reduce errors in the design process.

\subsubsection{Collision Check and Plan Optimization}

Traditional modeling methods tend to ignore the building materials and the internal space dimensions of the building, causing conflicts in construction operations, and these conflicting operations will only be exposed in the on-site construction, causing problems such as changes and waste. The commonly used collision detection software of BIM includes Navisworks, Revit, Fuzor, etc. Navisworks software can directly reflect the location of collision and the cause of collision. The construction unit imports the BIM model into the Navisworks software. The software will automatically display the location of the collision point, and issue a collision inspection report in Excel or a picture, and the relevant departments will perform inspection-modification-inspection until the collision result is displayed as zero. Through the application of BIM technology, avoid the occurrence of "errors, omissions, collisions, and deficiencies" [15].

\subsection{Application of BIM Technology in the Construction Phase of Prefabricated Buildings}

\subsubsection{Refined Management of Construction Site Layout}

Refined management of the construction site layout is very important to the assembly work of the prefabricated building construction site. Project equipment storage area, material stacking area and temporary facilities are all required to reasonably plan the site, and the virtual reality model system of BIM can realize the design of the overall model of the project, plan the layout of the site construction site, and clearly point out the stacking area of materials, equipment 
and temporary facilities. At the same time, tower cranes, transport vehicles, site road planning, operation routes and other data are input into the BIM system to carry out operation simulation, find out the conflict problems of construction operations, optimize and adjust in time, realize the fine management of the site layout of the construction site, accelerate the assembly process of prefabricated buildings, and improve the operating efficiency.

\subsubsection{Construction Schedule Simulation}

The BIM model can simulate the entire process of prefabricated building construction, and then guide the design, production and transportation of prefabricated components. The construction schedule plan can be produced by the Project management software Microsoft Project, while the construction schedule simulation needs to import the optimized three-dimensional information model of Revit and the construction schedule plan into Navisworks software and link them, and then conduct dynamic simulation of the construction process of each stage of the prefabricated building [16]. The construction schedule can be simulated by BIM technology, which can directly reflect the problems existing in the construction process, effectively arrange the construction process and the access of construction personnel, and avoid the occurrence of construction safety accidents.

\subsubsection{Virtual Animation Display}

Virtual animation display means that BIM information model is presented in the form of animation. The rendering software in BIM includes Lumion and 3DS Max, etc. [17]. Lumion software has the advantages of simple operation, good rendering effect, low requirement on computer hardware, and can realize dynamic model display. Import the.fbx file exported by the Revit software into the Lumion software, and add materials or modify the materials to the model through the software. After the materials are added, the architectural plan is displayed in the form of 3D renderings or animations. This "virtual animation" display method can detect in advance the technical problems, quality problems, and safety problems that may occur during the construction process, and can effectively avoid various problems in the actual construction stage.

\subsection{Application of BIM Technology in the Operation and Maintenance Phase of Prefabricated Buildings}

In the life cycle of construction facilities, operation and maintenance take the longest time and the cost is the highest. Therefore, the introduction of BIM technology will minimize the impact of manpower and material consumption on all aspects of the project, reducing the overall operation and maintenance costs of the project [18]. The integration of BIM has the application value of providing space management, providing facility management, providing hidden project management, providing emergency engineering management, and providing energy saving and emission reduction management. The specific operation method is 
to import the associated basic data in the design stage and the construction management stage into the operation database without error, and then combine the relevant network technology to control the operation of equipment, the energy consumption monitoring of the building, security and emergency evacuation management, etc. Find the defects of building components and equipment in time, determine the maintenance time, reduce the occurrence of accidents, and improve the maintenance efficiency at the same time. At present, BIM application stage generally exists in the design and construction stage, and BIM software has very poor interaction with other software in the operation stage, resulting in the insufficient application of BIM in the operation stage. It is still necessary to continue innovating software development and popularize the application in the operation and maintenance stage.

\section{Conclusions}

This paper analyzes the integrated application of BIM technology and prefabricated buildings through the application research of BIM technology in the prefabricated building design phase, construction phase, operation and maintenance phase and related software, and draws the following conclusions:

1) In the prefabricated building design stage, what BIM brings is informatized and refined modeling, which realizes the collaborative design of various professions and participants, and can realize parametric design, and quickly adjust the size of components and steel bars in large quantities. Layout, etc., perform simulation assembly before construction, collision inspection, pre-expose problems, and guide on-site installation work.

2) In the prefabricated building construction stage, use BIM to finely manage the layout of the construction site and optimize and adjust conflicting operations; Using BIM for construction simulation and real-time tracking of the whole construction process, problems existing in the construction process can be found in advance. The use of BIM technology for virtual dynamic display of the construction site, the above is conducive to the site construction staff to quickly, efficiently, high quality to complete the splicing assembly work, improve the work efficiency in the process of prefabricated building construction.

3) In the prefabricated operation and maintenance stage, BIM can be used to control equipment operation, building energy consumption monitoring, security and emergency evacuation management, etc., so as to find defects in building components and equipment in time, determine maintenance time, and reduce accidents. At the same time, the maintenance efficiency is improved.

4) In the whole life cycle of prefabricated buildings, BIM can better complete construction simulation, collision inspection and virtual animation display with the mutual cooperation of a variety of software. Revit software was used for modeling, Navisworks software was used for collision detection and scheme optimization, Navisworks software and MS Project software were used for construction simulation, Lumion software was used for virtual animation design. Therefore, 
the integrated application of BIM technology enables prefabricated buildings to achieve ideal results from design to construction, and has practical value for the construction of prefabricated buildings.

In short, the integrated application of BIM technology effectively improves the efficiency of prefabricated building design, production and construction, reduces construction costs and accident rates, achieves economical and safe construction effects, and has practical value for the construction of prefabricated buildings.

\section{Conflicts of Interest}

The authors declare no conflicts of interest regarding the publication of this paper.

\section{References}

[1] Ma, Y.H. (2021) The Practice and Application of BIM Technology in Prefabricated Building Design. China Construction Metal Structure, 4, 76-77.

[2] Wang, A.L., Su, M.Q., Sun, S.N. and Guo, L. (2020) Evaluation of BIM Application Capability of Prefabricated Buildings Based on Life Cycle Theory. Journal of Civil Engineering and Management, 37, 27-33+40.

[3] Xu, L.Q., Fu, M.Q. and Wang, C.C. (2021) Research on the Application of BIM Technology in the Safety Management of Prefabricated Buildings. Construction Economics, 42, 53-56.

[4] Xu, P.F., Li, J. and Sun, J.D. (2020) Research and Application of the Whole Process of Prefabricated Building Construction Based on BIM Technology. Building Structure, 50, 654-657.

[5] Gao, P., Wang, J., Wu, J.Y., Jiang, W.M., Yu, F.L., Sun, Y., Li, Q., Wang, S. and Yao, Y.W. (2019) BIM-Based Design of a Prefabricated Concrete Frame Structure and Analysis of Key Issues. Building Structure, 49, 562-567.

[6] Fan, H. (2017) AEC Seamless Link Promotes the Development of Prefabricated Buildings. Housing and Real Estate, No. 8, 61-64.

[7] Li, Y.P. and Chen, G.P. (2018) The Application and Development of BIM Technology in the Design of Prefabricated Concrete Buildings. Concrete, No. 6, 121-123.

[8] Wang, S.Q., Zhou, Q.H. and Tian, D.F. (2017) Research on the Application of BIM Technology in Prefabricated Construction Projects under the Background of General Engineering Contracting. Journal of Engineering Management, 31, 39-44.

[9] Tang, Y.J. (2020) Development and Prospect Analysis of My Country's Prefabricated Buildings. Ceramics, 4, 9-11.

[10] Chen, Y.J., Xu, Q. and Xu, G.S. (2020) Talking about Prefabricated Building. JiangXi Building Materials, 4, 9+11.

[11] Hao, X.L. (2021) Discussion on the Application of BIM Technology in the Construction of Prefabricated Construction Projects. China Construction Metal Structure, 4 , 94-95.

[12] Jiang, L., Zhang, Z.Y., Zhang, L. and Yang, Z.Y. (2012) Application of BIM Technology in PKPM Construction Engineering Software System. Civil Engineering Information Technology, 4, 78-87.

[13] Hu, B. (2021) Research on the Application of Refined Construction Management of Prefabricated Buildings Based on BIM Technology. China Construction Metal Struc- 
ture, 4, 19-21.

[14] Wang, H. (2021) Research on the Application of BIM Technology in the Design and Construction of Prefabricated Buildings. Civil Engineering Information Technology, 1-10. http://kns.cnki.net/kcms/detail/11.5823.TU.20210519.1332.002.html

[15] Liu, D.D., Zhao, Y.S., Yue, Y.Y., Du, K. and Guo, Y.T. (2017) The Application of BIM Technology in the Design and Construction of Prefabricated Buildings. Building Structure, 47, 36-39+101.

[16] Shu, X., Zhang, Y. (2018) Research on the Design and Construction of Prefabricated Buildings Based on BIM Technology. Building Structure, 48, 123-126+91.

[17] Zhang, Z. (2021) Research on the Whole Process of Smart Construction of Prefabricated Buildings Based on BIM. Shanxi Architecture, 47, 9-11+16.

[18] Zhang, Y. (2020) The Application of BIM Technology in Prefabricated Buildings. Sichuan Building Materials, 46, 47-48. 